\title{
PLASMA BOUNDARY EXPERIMENTS ON DIII-D TOKAMAK
}

by

M. Ali MAHDAVI, N. BROOKS, D. BUCHENAUER, * A. FUTCH, ${ }^{\dagger}$ D.N. HILL, $\dagger$ J. HOGAN, $\ddagger$ G.L. JACKSON, A. LANGHORN, B. LEIKIND, S. LIPPMANN, J. LUXON, G. MATTHEWS, M. MENON, $\ddagger$ P. MIODUSZEWSKI, L. OWEN, $\ddagger$ P. PETERSEN, T. PETRIE, M. RENSINK, $\dagger$ R.D. STAMBAUGH, T.C. SIMONEN, G. STAEBLER, DIII-D PHYSICS GROUP, and ADP COLLABORATORS

This is a preprint of an invited paper to be presented at the Ninth !nternational Conference on Plasma Surface Interactions iri Controlled Fusion Devices, May 20-25, 1990, in Bournemouth, United Kingdom and to be printed in the Proceedings.

Work supported by U.S. Department of Energy Contract DE-AC03-89ER51114

* Sandia National Laboratories, Livermore, CA.

† Lawrence Livermore National Laboratory, Livermore, CA.

$\$$ Oak Ridge National Labc.atory, Oak Ridge, TN.

II JET Joint Undertaking, UK.

GENERAL ATOMICS PROJECT 3466

JUNE 1990

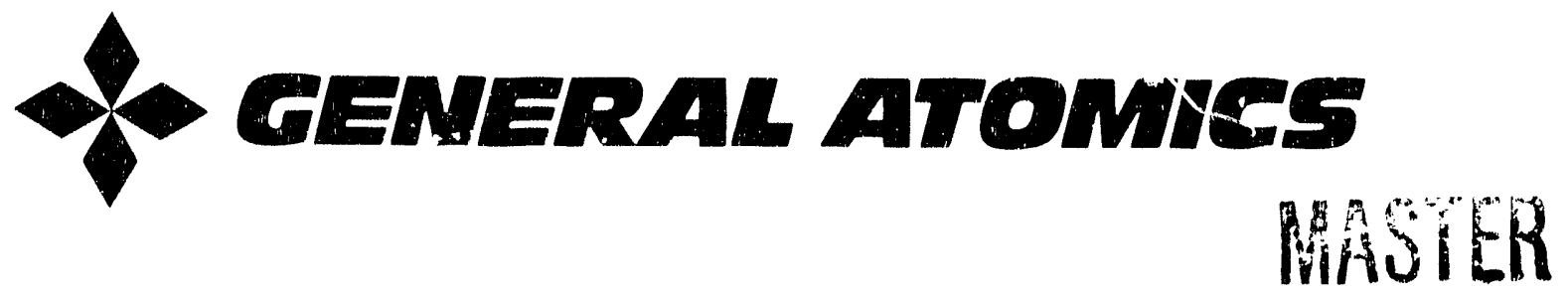




\begin{abstract}
A survey of the boundary physics research on the DIII-D tokamak and an outline of the DIII-D Advanced Divertor Program (ADP) is presented. We will present results of experiments on impurity control, impurity transport, neutral particle transport, and $p_{i}$ ticle effects on core confinement over a wide range of plasma parameters, $\mathrm{I}_{\mathrm{p}} \lesssim 3 \mathrm{MA}, \beta_{T} \lesssim 10.7 \%, \mathrm{P}$ (auxiliary) $\lesssim 20 \mathrm{MW}$. Based on the understanding gained in these studies, we in collaboration with a number of other laboratories have devised a series of experiments (ADP) to modify the core plasma conditions throuch changes in the edge electric field, neutral recycling, and plasma surface interactions.
\end{abstract}

\title{
DISCLAIMER
}

This report was prepared as an account of work sponsored by an agency of the United States Government. Neither the United States Government nor any agency thereof, no: any of their employees, makes any warranty, express or implied, or assumes any legal liability or responsibility fur the accuracy, completeness, or usefulness of any information, apparatus, product, or process disclosed, or represents that its use would not infringe privately owned rights. Reference herein to any specific commercial product, process, or service by trade name, trademark, manufacturer, or otherwise does not necessarily constitute or imply its endorsement, recommendation, or favoring by the United States Government or any agency thereof. The views and opinions of authors expressed herein do not necessarily state or reflect those of the United States Government or any agency thereof. 


\section{CONTENTS}

ABSTRACT ......................... . . . . . . . .

1. INTRODUCTION . . . . . . . . . . . . . . . 1

2. IMPURITY CONTROL . . . . . . . . . . . . . 3

3. IMPURITY TRANSPORT . . . . . . . . . . . . . . . . . 9

4. DIVERTOR HEAT FLUX DISTRIBUTION . . . . . . . . . . 13

5. PARTICLE BALANCE AND DENSITY BEHAVIOR . . . . . . . 17

6. NEUTRAL EFFECTS ON H-MODE CONFINEMENT . . . . . . . 19

7. FUTURE PLANS . . . . . . . . . . . . . . . . 25

8. SUMMARY . . . . . . . . . . . . . . . . . . 29

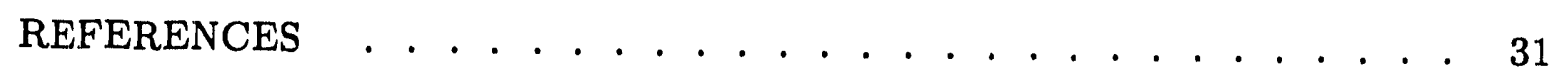

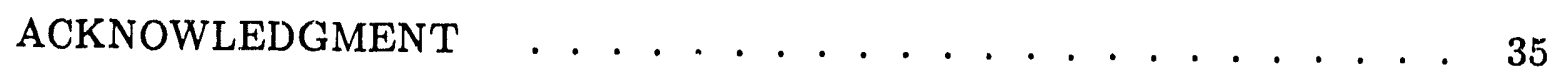




\section{LISTI OF FIGURES}

1. RGA data, obtained during various stages of vessel conditioning following a long duration vent, showing peaks due to oxygen and $\mathrm{CO}_{2}$. . 4

2. $Z_{\text {eff }}$ as a function of line average density for $\mathrm{H}$-mode deuterium plasmas with deuterium NBI

3. A comparison of temporal behavior of intensities of Ni-XVII and $\mathrm{Ni}$-XXVI lines for two $\mathrm{H}$-mode plasmas, one with a hollow density profile and one with a flat profile

4. Plots of heat flux to the divertor tiles as a function of sine of the angle of incidence of the field lines on the tiles for several times, during the current ramp phase of an ohmic plasma.......

5. Time histories of divertor current for an unbiased single-null plasma

6. Electron density behavior in NBI, ECH, and ohmically-heated plasmas . . 18

7. Time histories of plasma parameters for two $\mathrm{H}$-mode shots with and without gas puffing

8. Radiated power densities for shots 62630 and 62628 , obtained at $\mathrm{T} \sim 2.9 \mathrm{~s}$

9. Views of the ADP hardware 


\section{INTRODUCTION}

During the past two years, since the last PSI conference, the operating range of the DIII-D plasma parameters has been significantly expanded. Plasma currents of $I_{p}=3 \mathrm{MA}, \beta_{\mathrm{T}}$ of $10.7 \%$, and $T_{1}=17 \mathrm{kV}$ have been achieved. The current flat top was extended to 10 seconds, and ten second long quasi steady-state $\mathrm{H}$-mode plasmas with $50 \mathrm{MJ}$ of auxiliary heating power were demonstrated. These achievements are partly owed to the understanding and management of plasma wall interactions, and impurity and particle control techniques. Helium glow discharge cleaning [1] and impurity control techniques based on ELM effects, and wall conditioning were indispensible for attainment of the long pulse $\mathrm{H}$-mode. Carbonization [2] was instrumental in extending $T_{i}$ and $I_{p}$ to the new high values. Uniform distribution of the exhaust heat on the divertor tiles was necessary for long-pulse high-power operations.

In the first half of this paper, Sections 1-5 we will present an overview of the recent DIII-D results on topics of impurity control and transport, divertor heat flux measurements, and particle transport. Since the great majority of our data have been obtained in the $\mathrm{H}$-mode, unless otherwise noted we present only the $\mathrm{H}$-mode results.

The topics covered in Sections 1-5 are within the traditional scope of the boundary physics. Observations on DIII-D [3,4] and several other devices [4--5], and recent theoretical considerations [6,7], strongly suggest that $\mathrm{H}$-mode transition is due to processes within a few poloidal gyroradii of the plasma boundary. This region has considerable overlap with the radiative zone of the low- $Z$ impurities and the recycling neutral ionization profile. Therefore, it is plausible to expect plasma wall interactions, which determine impurity and particle sources in the edge plasma can have major impacts on the core plasma transpert properties.

These considerations point out that the boundary plasma should not be viewed only as a passive conduit for heat and particle exhaust. Boundary plasma effects on core confinement and stability need to be investigated, and methods of enhancing the core plasma properties through boundary effects should be considered. In Section 6 we will discuss the effects of neutrals on $\mathrm{H}$-mode confinement. A possible explanation 
for the deleterious effect of neutrals on confinement is suggested. The balance of the paper is devoted to a discussion of several particle control and divertor biasing experiments planned for DIII-D which are intended for modifying the core plasma properties through boundary effects. 


\section{IMPURITY CONTROL}

A combination of standard high vacuum practices, vessel bakeout, Taylor discharge cleaning and/or glow wall conditioning is normally sufficient to keep impurity content of the DIII-D plasmas at an acceptable level [8]. Following major vent, the vessel is initially pumped for 24 hours, and then it is baked for $\sim 40$ hours at $\$ 400^{\circ} \mathrm{C}$ followed by 24 hours of discharge cleaning, using a combination of helium glow, hydrogen glow, or Taylor discharges. Figure 1 displays RGA data, obtained during various stages of the vessel conditioning following a long duration vent, showing the progress in the vessel cleanup. The figure displays RGA peaks due to oxygen (mass 18) and $\mathrm{CO}_{2}$ (mass 44). Partial pressures of both species drop significantly after one or two baking cycles, but then saturate until the application of TDC. The RGA data do not show an appreciable effect due to He glow; however, the effect of He glow is much more noticeable on the performance of the plasma. Under normal operating conditions, the dominani impurities are carbon and nickel sputterea from the vessel walls, and oxygen is only a minor contributor to $Z_{\text {eff }}$ and radiative losses. Table 1 lists the type, quantity, and suspected source of impurities identified in XUV radiation spectra of DIII-D discharges.

Under normal operating conditions, typically less than $30 \%$ of the input power is lost through core plasma impurity radiation and $Z_{\text {eff }} \lesssim 2$. However, under certain operating conditions (see below) a high concentration of metallic impurities causes a deterioration of the global confinement, and even radiative collapse. In order to reduce the metallic content of plasma, we have recently supplemented the normal wall conditioning procedure with a carbonization process similar to that prescribed by Winter $[2,9]$. In order to reduce the hydrogen content of the carbonized surfaces, carbonization was followed by several hours of vessel bake at $350^{\circ} \mathrm{C}$ and 30 minutes of He Glow cleaning. This procedure reduced the metallic impurity content of DIII-D plasmas an order of magnitude [2], without any adverse side effects such as increased plasma fueling. In addition, carbonization reduced the intensity of oxygen lines. The effect of carbonization lasts for $\sim 100$ shots for metallic impurities and oxygen. Carbonization has allowed a significant expansion in the DIII-D parameter. 


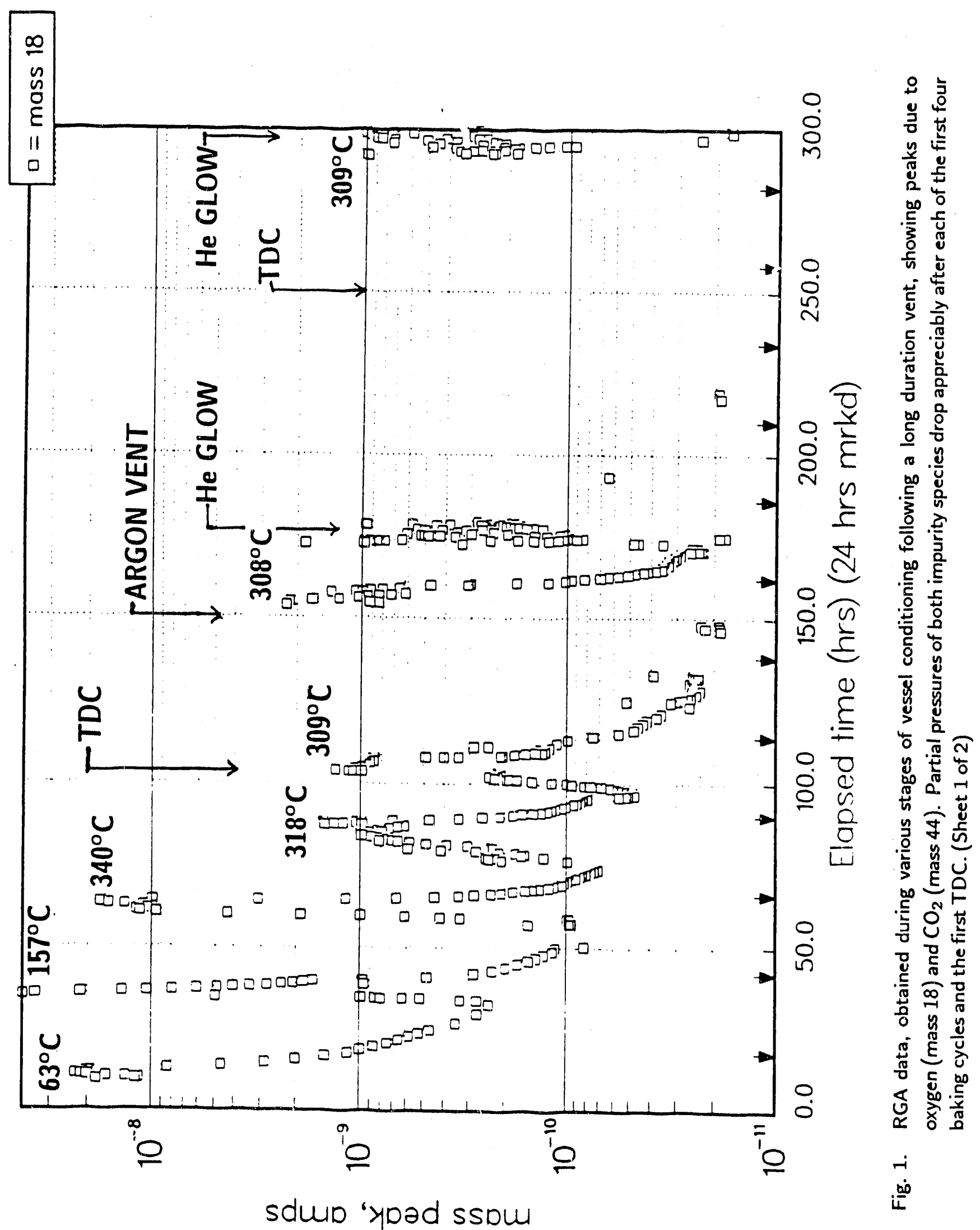




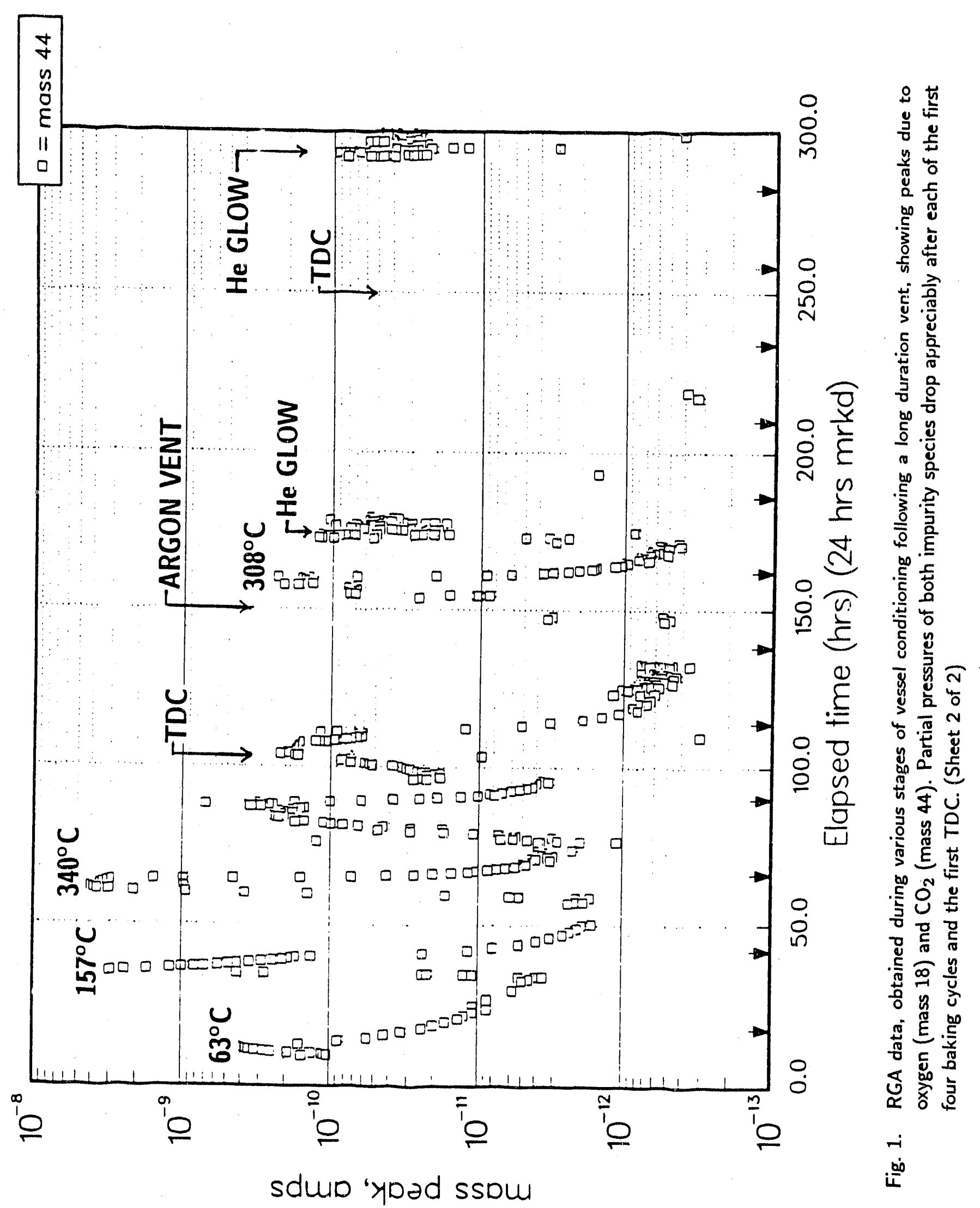




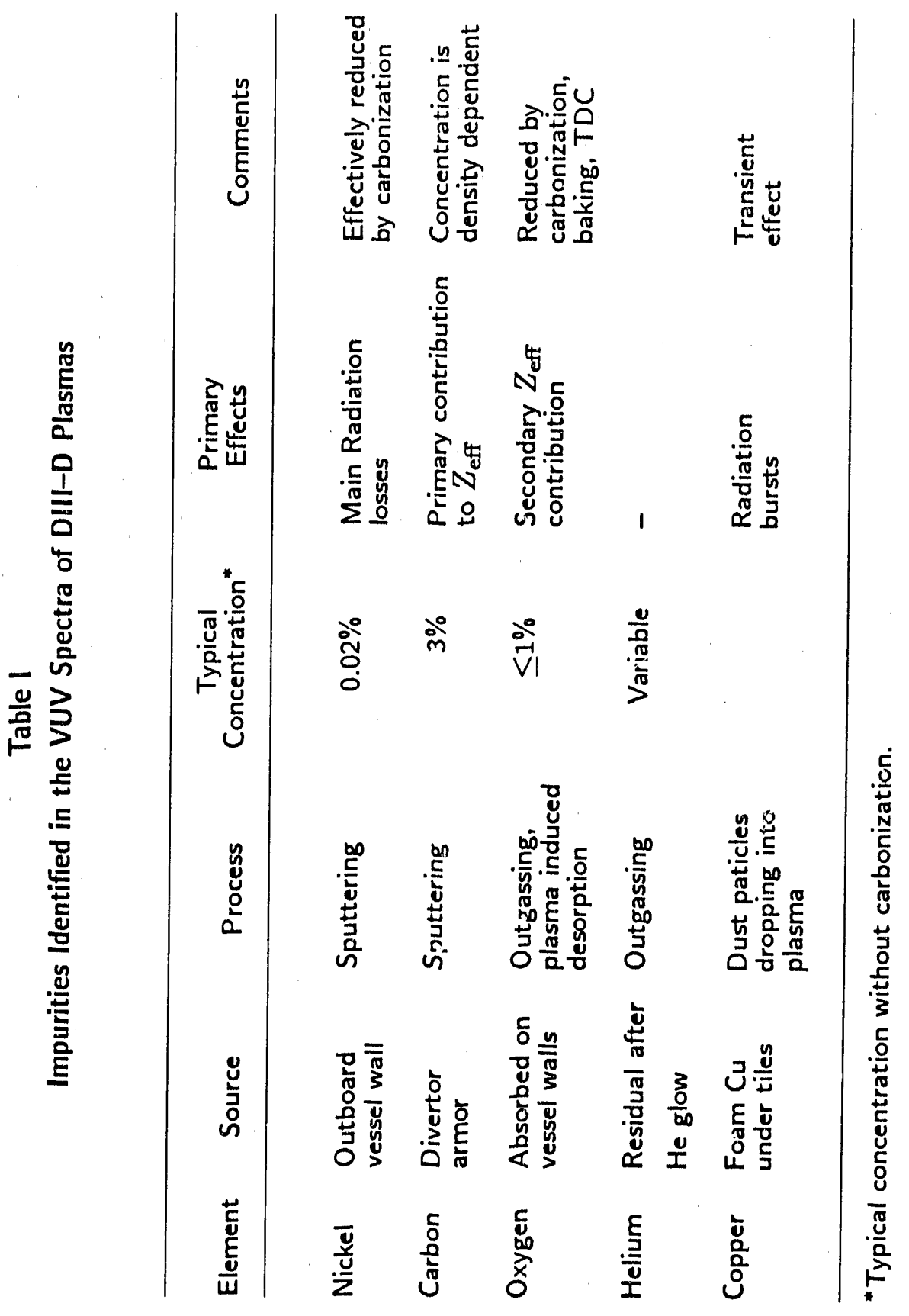


Carbon, sputtered from the graphite divertor tiles, is the main contributor to $\mathrm{Z}_{\text {eff }}$. As shown in Fig. 2, $\mathrm{Z}_{\text {eff }}$ is a strongly decreasing function of the line average electron density, and is relatively insensitive to the gross heating power. The dependence of $\mathrm{Z}_{\text {eff }}$ on $\bar{n}_{e}$ is consistent with the tendency of the divertor plasma density to increase with the line average density, resulting in enhancement of the divertor impurity shielding efficiency [10]. Owing to a roughly uniform spreading of the transported heat flux over a large divertor target area, we have been able to operate long pulse plasmas with up to $50 \mathrm{MJ}$ gross input power, without any indication of carbon bloom.

In a great majority of the DIII-D plasmas, nickel, sputtered from the outboard vessel wall, accounts for most of the radiative losses. Nickel transport in $\mathrm{H}$-mode plasmas is influenced to a high degree by the Edge Localized Modes (ELMs), and the electron density profile. In general, during the ELM-free periods, the nickel content of plasmas increases linearly with time. With a sufficiently long ET,M-free period, the radiative losses in the core plasma can exceed the auxiliary heating power and result in radiative collapse or loss of the $\mathrm{H}$-mode. In most shots, with the onset of ELMs, the impurity content of the plasma reaches a plateau or even starts to decrease.

Taking ad antage of the impurity exhaust property of ELMs, we have succeeded in limiting the impurity content of $\mathrm{H}$-mode plasmas and obtained long pulse $\mathrm{H}$-mode plasmas with nearly stationary impurity and density profiles $[11,12]$. 


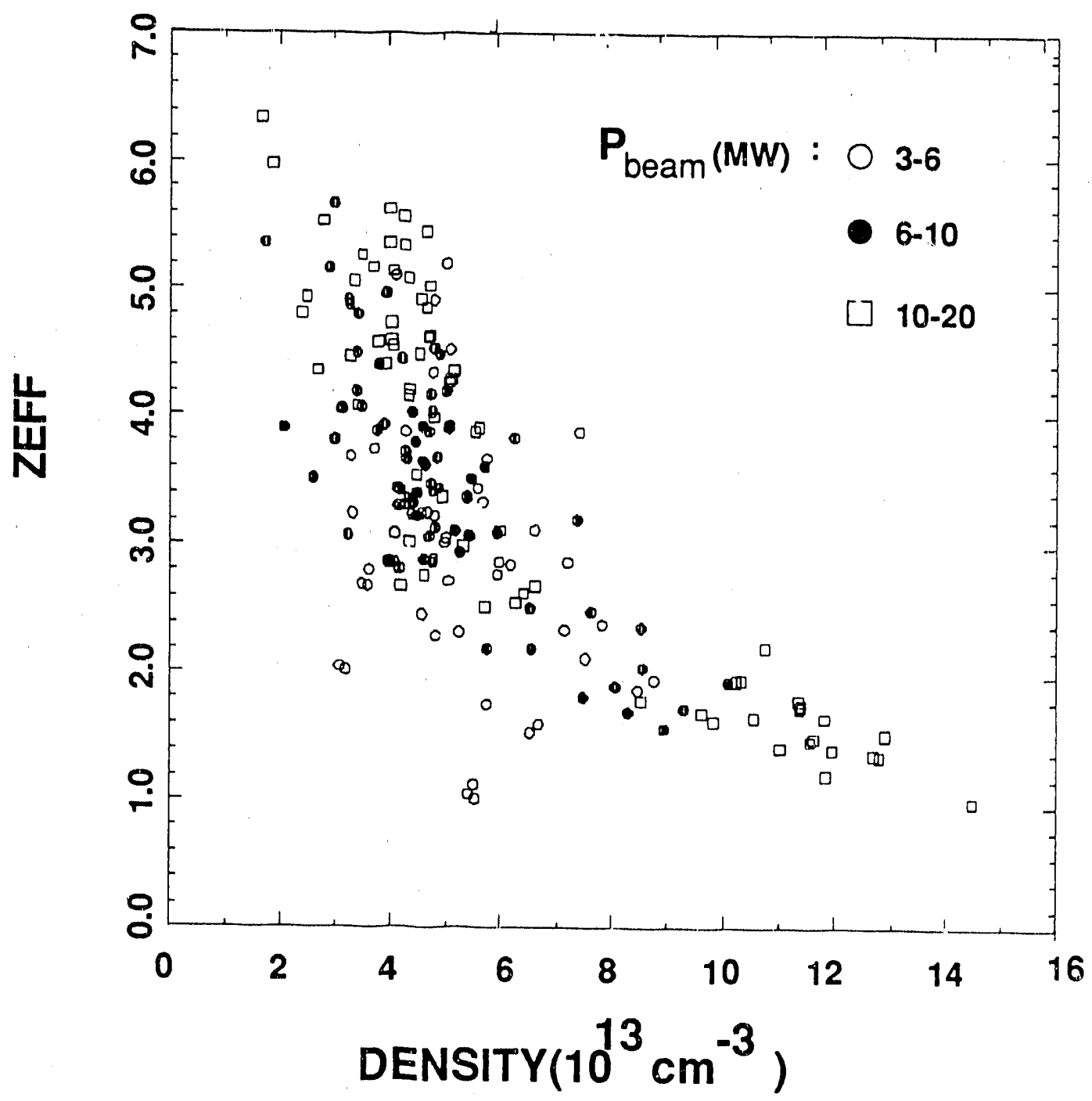

Fig. 2. $Z_{\text {eff }}$ as a function of line average density for $\mathrm{H}$-mode deuterium plasmas with deuterium NBI. $Z_{\text {eff }}$ decreases with increasing line average electron density and is relatively insensitive to the level of heating power. 


\section{IMPURITY TRANSPORT}

The core plasma impurity transport is strongly density dependent. Figure 3 compares line intensi,ies of an edge charge state (Ni XVII) and a central charge state of nickel ( $\mathrm{N}: \mathrm{XXVI}$ ) of a plasma with a hollow density profile with that of one with a flat profile. The corresponding density profiles are shown in Fig. 3(b). The $\mathrm{Ni}$ XVII line intensities for these shows are very similar, whereas the line intensity of nickel XXVI in the shot with peakea $n=$ profile (shot 68123 , dashed lines) saturates at $t=2000 \mathrm{~ms}$, while that of the shot 68108 , with flat density profile, is rising. The contrast between thess shots is even stronger when we take into consideration the high ELM activity of the shot 68108 , as compared with a single ELM in shot 68123 . The ineffectiveness of ELMs in reducing the nickel content of shot 68108 is attributed to peaking of the nickel profile which reduces the nickel density within the range of ELMs.

The qualitative observations of the previous paragraph are in agreement with transpori analysis of the impurity line intensities with the aid of the MIST [13] impurity transport code. It has been shown [14] that a model assuming a constant

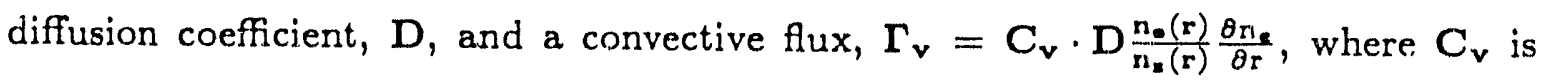
a proportionality constant, can be used to simulate the temporal behavior of ELM modulated impurity lines. The equilibrium impurity profiles for this choice of transport model assume a neoclassical-like form of $n_{\mathbf{z}}(r)=\left[n_{\mathbf{e}}(r)\right]^{C_{\mathbf{v}}}$. Using this model for time dependent analysis of ELM modulated impurity line intensities, a diffusion coefficient $D=1 \mathrm{~m}^{2} / \mathrm{s}$, and a convective term of $\Gamma_{\mathrm{v}}=3 \cdot \mathrm{D} \frac{n_{\mathrm{e}}(\mathrm{r})}{n_{\mathrm{n}}(\mathrm{r})} \frac{\partial_{\mathrm{e}}}{\partial_{\mathrm{r}}}$ has been deduced. The calculated equilibrium impurity profiles, using these values of $D$ and $C_{V}$ are in 


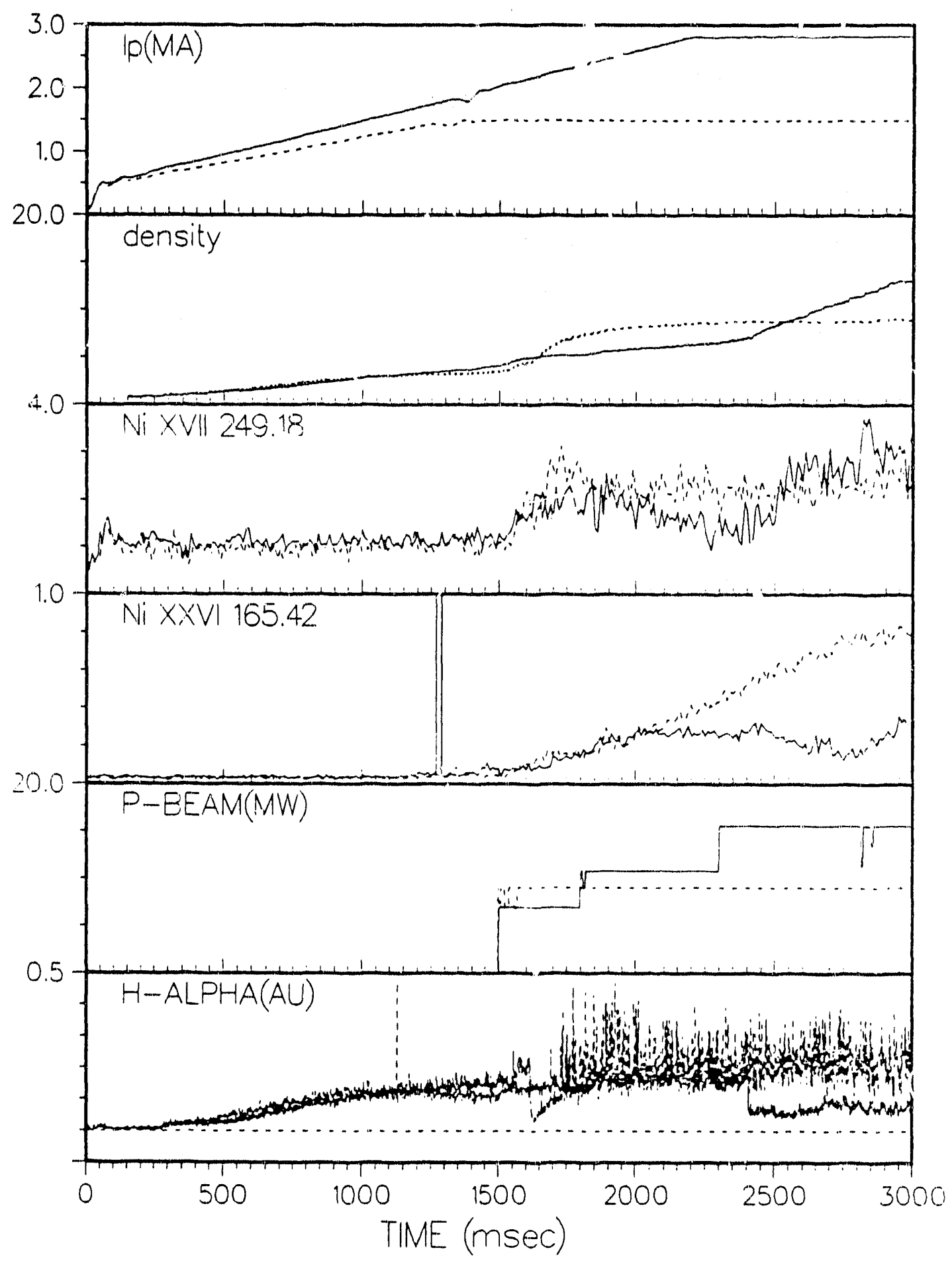

Fig. 3(a). A comparison of temporal behavior of internsities of $\mathrm{Ni}-\mathrm{XVII}$ and $\mathrm{Ni}-\mathrm{XXVI}$ lines for two $\mathrm{H}$-mode plasmas, one with a hollow density profile (solid) and one with a flat profile (dashed). The line intensity of the Ni-XVII (an edge specie) line for the two shots are nearly equal whereas the intensity of $\mathrm{Ni}-\mathrm{XXVI}$ (central specie) in the shot with flat density profile is greater than that of the one with hollow density profile by a factor significantly greater than the ratio of the local electron densities in the two shots. 

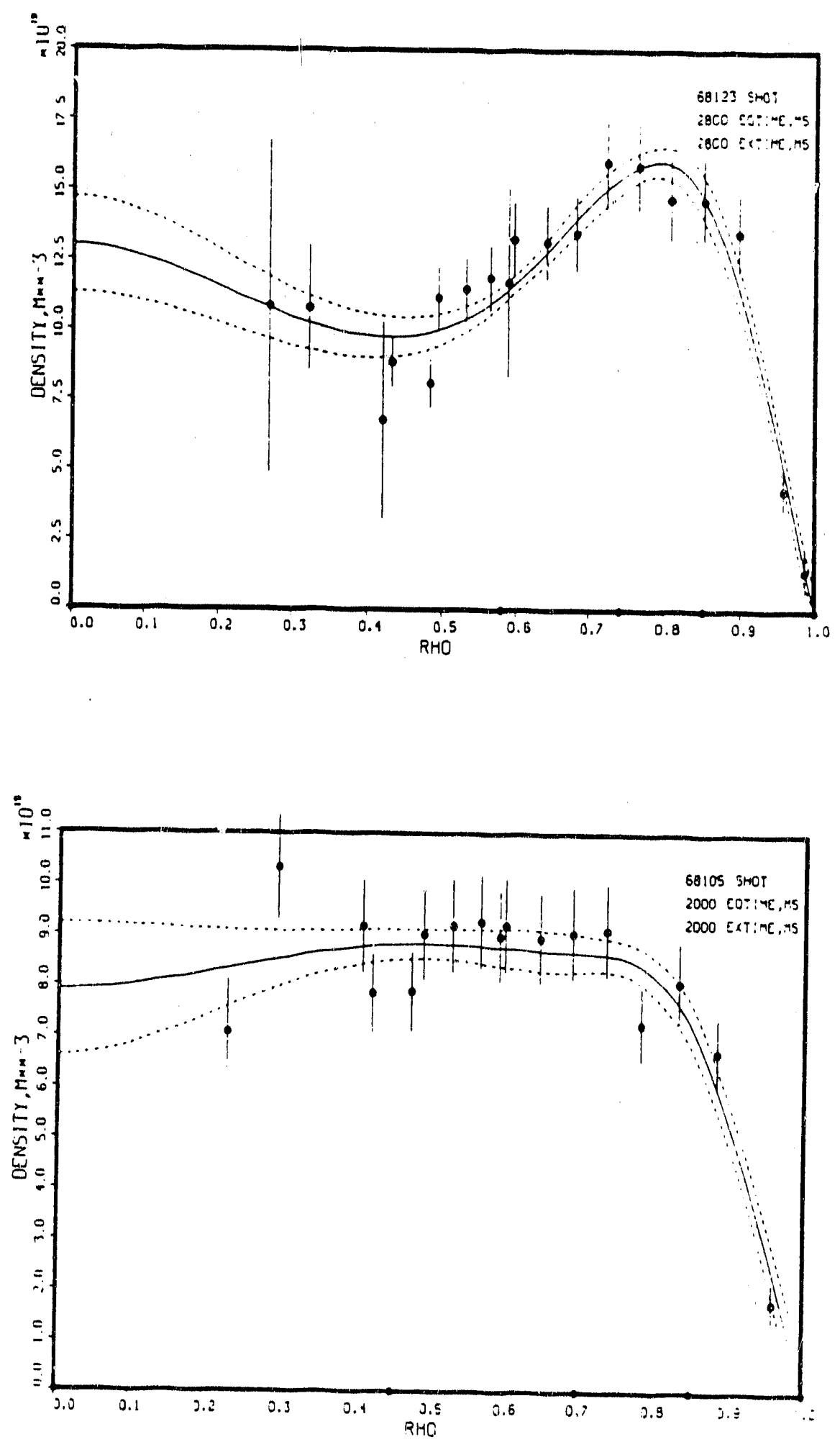

Fig. 3(b). Electron density profiles corresponding to the H-mode shots of Fig. 3(a). 
good agreement with profiles determined by an independent method, using radiation profiles measured by arrays of bolometers and visible bremsstrahlung detectors [15]. 


\section{DIVERTOR HEAT FLUX DISTRIBUTION}

Heat flux to the divertor tiles is measured by an IR TV camera system [16], sensitive to radiaton in the $8-12 \mu$ range.

The divertor heat flux distribution depends on the direction of the ion $\nabla B$ drift relative to the $\mathrm{X}$-point position. In general, the heat flux distribution is sharply peaked around the separatrix intercept points on the divertor target plates. With the ion $\nabla \mathrm{B}$ direction pointing towards the $\mathrm{X}$-point, more heat flows to the outer in'ercept and the profile is narrower than the inner one. This in-out imbalance in the total power is greatest in the $\mathrm{L}$-mode shots, reaching as high as 4 . With the opposite toroidal field direction, the in-out imbalance in the total heat flux nearly disappears and the profiles become similar. These observations are in qualitative agreement with the theoretical work of Staebler [17], which considers asymmetries due to neoclassical particle drifts. Increased particle flux into the inboard divertor leg enhances the geometrical effects to broaden and reduce the heat deposition on the inner tiles when the ion $\nabla B$ direction points toward the separatrix, and opposes it with the opposite sense of the toroidal field. Efforts are underway to incorporate the particle drift effects and electric field effect(see below) in to the B2 code [18-21].

Small misalignments or gaps between the divertor tiles results in significant deviation from the average heat flux. The relative alignment accuracy of the DIII-D divertor is $\delta \theta= \pm \sim 1$ degree which is comparable to the mean angle of the field lines, $\Theta \sim 1$ degree, relative to the divertor plates. The power tiax to the divertor tiles is accurately described by the $\sin (\Theta-\delta \theta)$ distribution. Figure 4 displays plots of heat flux to a number of diverior tiles, versus $\sin (\Theta-\delta \theta)$, during the current ramping phase of an ohmically heated plasma. As shown, the effect of misalignment of $1^{\circ}$ 


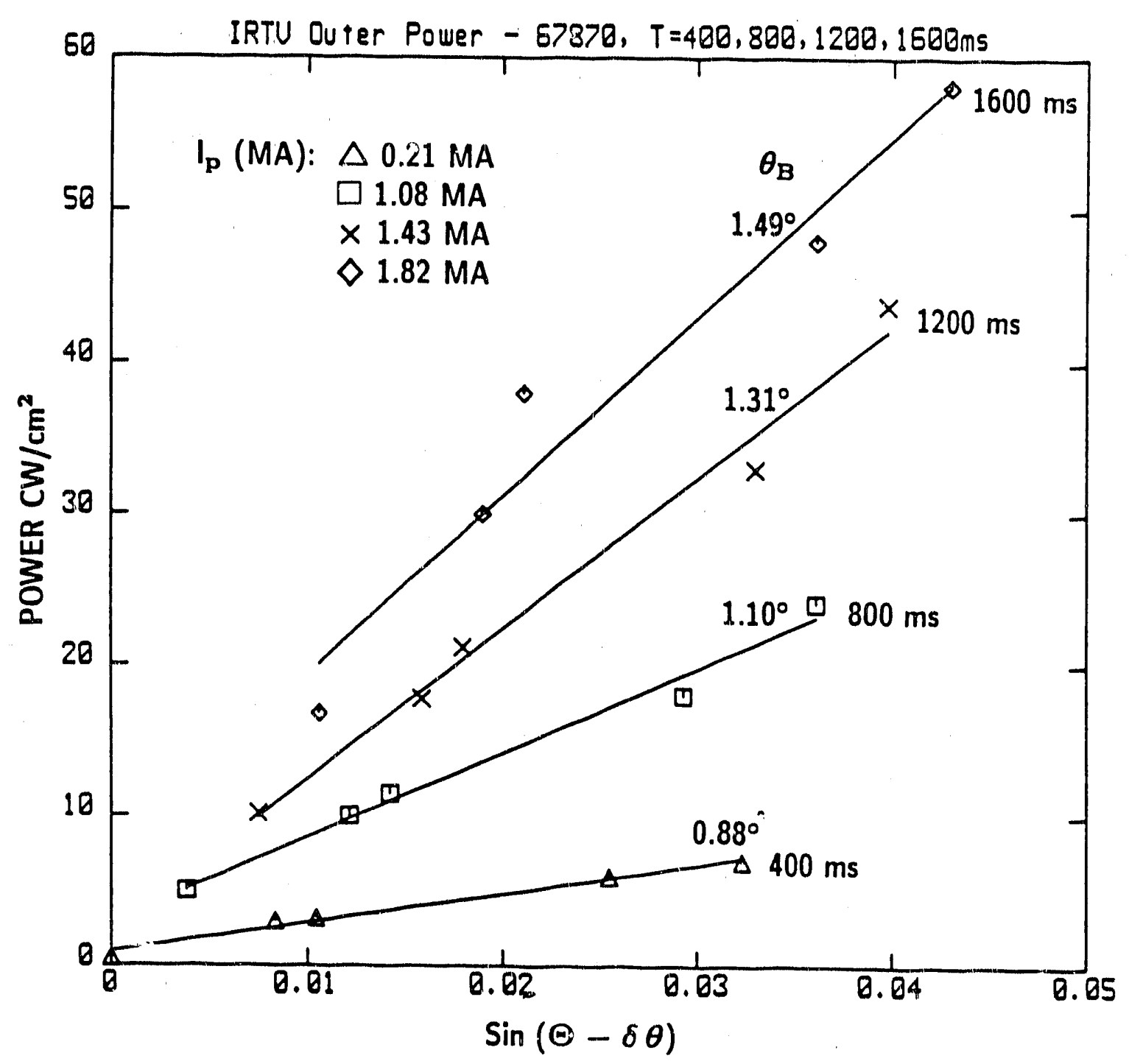

Fig. 4. Plots of heat flux to the divertor tiles as a finction of the Sine of the angle of incidence of the field lines on the tiles for several times, during the current ramp phase of an ohmic plasma. Tile misalignments of the order of 1 degree result in heat flux variations of about a factor of two. 
of the tiles on heat flux is a bout a factor of two. This effect is current dependent, decreasing with increasing $I_{p}$, since, for a given $B_{T}$ and plasma configuration, $\Theta$ increases with increasing poloidal field. These observations indicate that in the design of the next generation machine details of the geometry of the divertor armor need to be consir ed.

The heat flux imbalance between the inner and outer divertor legs is expected to drive a thermoelectric current from one divertor leg to the other [22-24]. In DIII-D, current flow to the divertor tiles is deduced from measurement of voltage across siunt resistors between the divertor tiles [25], which are otherwise insulated from the vessel, and the vessel. This system can measure currents in the range of 1-10,000 amperes per tile. Figure 5 shows data from a typical unbiased single-null beam-heated divertor plasma, where a current of $\simeq 2 \mathrm{kA}$ flows in the SOL plasma from the inner (colder) divertor leg to the outer (hotter) divertor leg. The thermoelectric current during the L-mode phase $(t=800-1600 \mathrm{~ms})$ is more than twice that of the ohrilic phase of the plasmas. With the injection of additional beam power at $t=1600 \mathrm{~ms}$, a transitinn to the $\mathrm{H}$-mode occurs, resulting in a reduced heat flux imbalance, and thereby a lower divertor current. The direction and magnitude of the measured current are in qualitative agreement with the predicted currents due to thermoelectric effects [22]. 


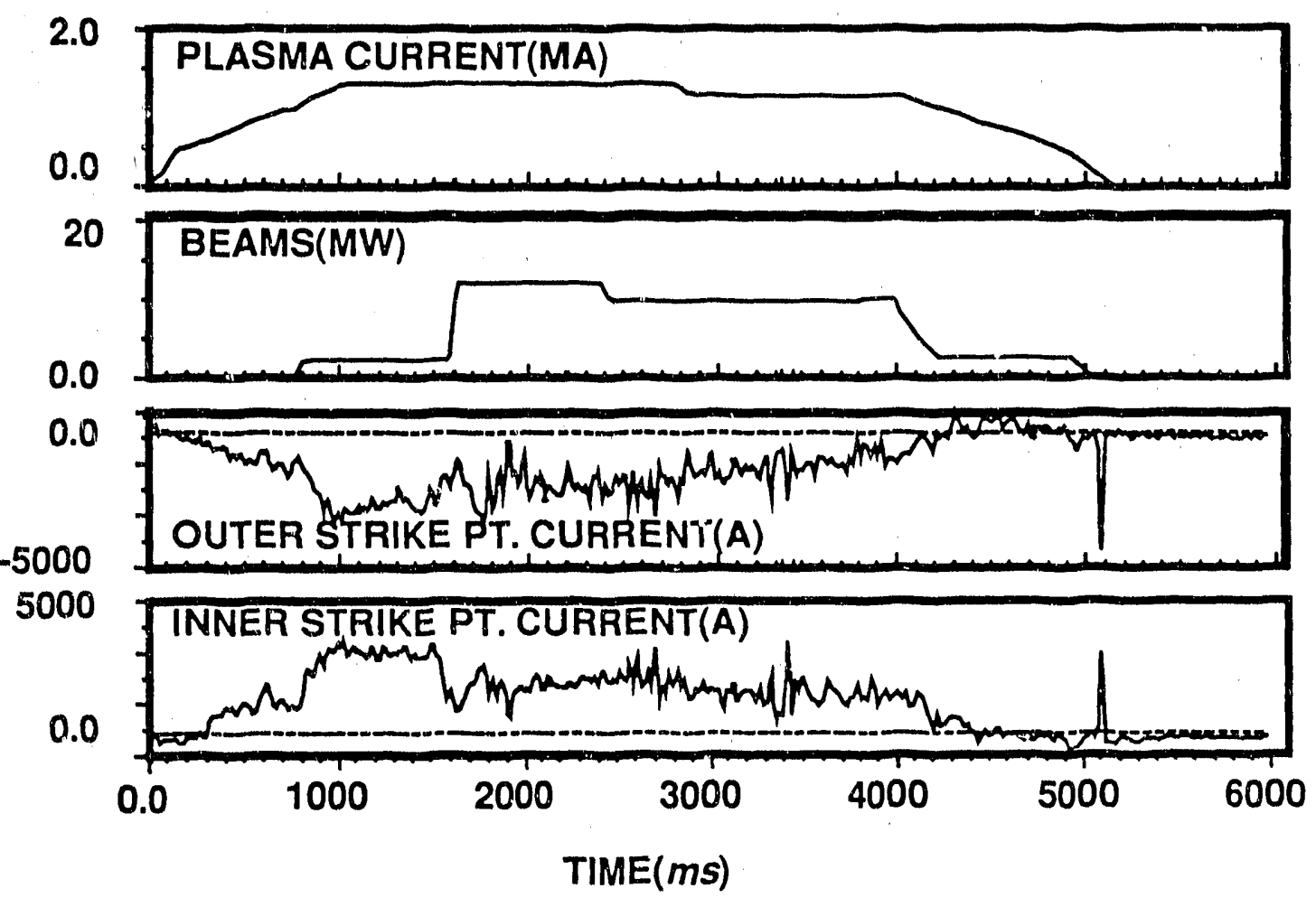

Fig. 5. Time histories of divertor current for an unbiased single-null plasma. During the L-mode phase $(t=0.8-1.6 \mathrm{~s})$ a current of $\simeq 2 \mathrm{kA}$ flows in the SOL from the inner leg of the divertor to the outer leg. The current is reduced with the onset of $\mathrm{H}$-mode at $t=1.6 \mathrm{~s}$. 


\section{PARTICLE BALANCE AND DENSITY BEHAVIOP}

A common characteristic of all DIII-D H-mode plasmas is a rapid rate of density rise at the $\mathrm{L}-\mathrm{H}$ transition which can not be accounted for by the known external particle sources. Figure 6 demonstrates this characteristic for ohmic, ECH, and neutral beam heated $\mathrm{H}$-mode plasmas. In beam heated plasmas the initial rate of density rise is typically 20-100 Torr $1 / \mathrm{s}$, corresponding to 1 to 4 times the beam particle input. With the onset of ELMs, the rate of density rise drops to a small fraction of the external sources. These observations are indicative of a two way transfer of particle between the plasma and the vessel walls. Particles stored in the SOL and divertor plasmas, or as neutrals within the vacuum envelope can account for no more than $3.5 \%$ of the density rise.

A global model, similar to that used by Refs. [26] and [27], assigning a confinement time to particles stored in the graphite tiles, adequately describes the density behavior of the DIII-D shots [11]. According to this model, a factor of two improvement in the plasma particle confinement time at the L-H transition breaks the equilibrium particle balance of the plasma-wall system, causing a transfer of particles from the wall to the plasma.

Depending on the wall condition, the details of plasma initiation, and plasma current, $\mathrm{H}$-mode density profiles in DIII-D vary from moderately peaked to markedly hollow, but always with a large density gradient within a couple of centimeters of the separatrix. Particle transport analysis, using the the ONETWO transport code and the DEGAS Monte-Carlo neutral code [20] show that the density profile evolution in the $\mathrm{H}$-mode plasmas can be well described by a constant particle diffusivity of $0.5 \mathrm{~m}^{2} / \mathrm{s}$ and an inward pinch velocily of $20 \mathrm{~m} / \mathrm{s}$ at the plasma boundary. 


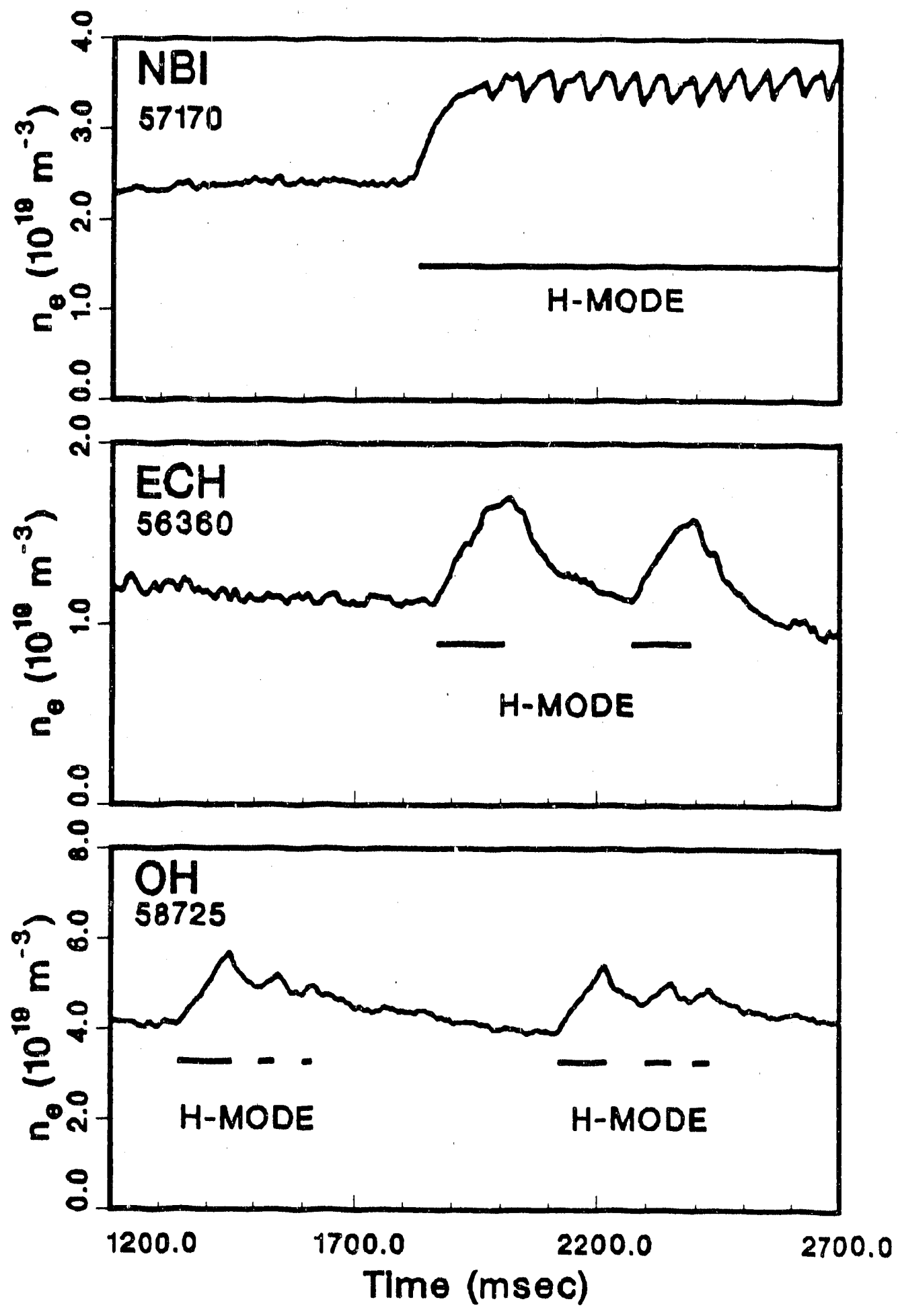

Fig. 6. Electron density behavior in NBI, ECH, and ohmically-heated plasmas. The initial rate of density rise in all cases exceeds the external particle sources. 


\section{NEUTRAL EFFECTS ON H-MODE CONFINEMENT}

Observation on several machines show that a sufficiently high influx of neutral gas can inhibit $\mathrm{H}$-mode transition, reduce energy confinement time during the $\mathrm{H}$-mode, or cause a transition from the $\mathrm{H}$ - to the $\mathrm{L}$-mode $[28,29]$. The process through which neutrals affect the $\mathrm{H}$-mode confinement is not well understood. Postulates put forward to explain the deleterious effect of the neutrals include increased edge collisionality, exceeding the density limit, and excessive core radiation losses. Here we will show that DIII-D data are consistent only with the first of the the above postulates. In addition, we will show that a possible mechanism through which the neutrals affect $\mathrm{H}$-mode confinement is their contribution to the poloidal angular momentum loss in the plasma boundary.

In Fig. 7, plasma characteristics of a DIII-D H-mode shots with gas puffing (shot 62630 ) at the rate of $\sim 30$ Torr $1 / \mathrm{s}$, beginning at $t=1.7$ seconds, is compared with a reference shot (62628). Except for a lower neutral beam power, the other external parameters of the two shots are nearly identical. During the gas puffing phase of shot 62630 , divertor neutral pressure builds up at nearly a constant rate, until a transition back to the L-mode occurs. At this time the neutral flux into the core plasma, is estimated to be of the order 350 Torr $1 / \mathrm{s}$, at a time that the rate of density rise corresponds to less than 2 Torr $1 / \mathrm{s}$. The direct power loss due this rate of neutral flux corresponds to approximately ten percent of the power flow through the plasma boundary.

First we rule out the possibilities that either core radiative losses, or density limit is the primary cause of H-L transition. Until $t=3.2 \mathrm{~s}$, when shot 62630 reverts back to the L-mode, the energy confinernent time, and the the magnitude and the 


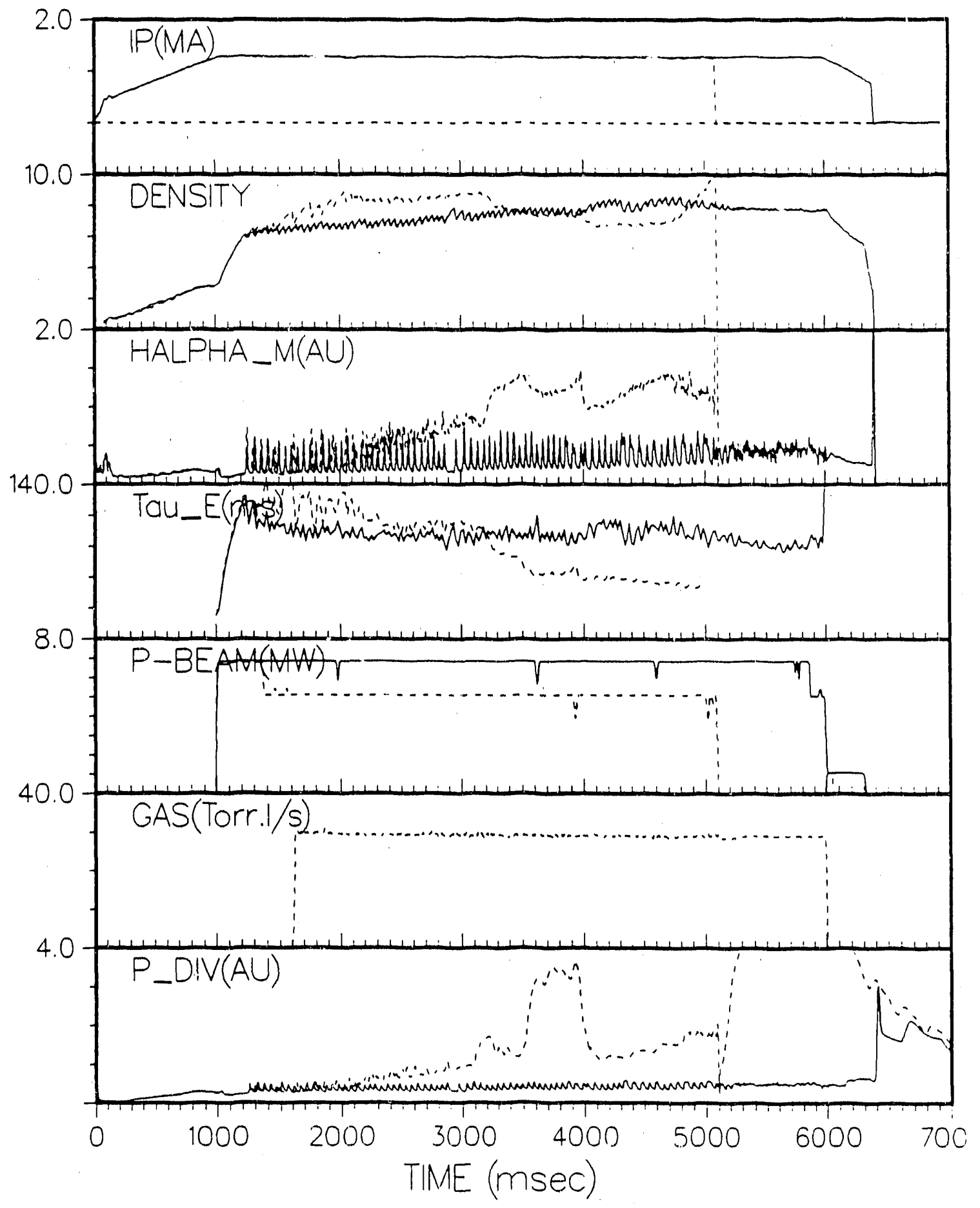

Fig. 7. Time histories of plasma parameters for two $\mathrm{H}$-mode shots with (dashed) and without (solid) gas puffing. A soft transition to L-mode occurs during gas puffing at $t=$ $3.1 \mathrm{~ms}$, as seen on the energy confinement time trace $\left(\tau_{E}\right)$. 
radial profile of the radiated power of 'he two shots, as measured by a 21 channel bolometer array, are very similar (Fig. 8). Therefore, the primary effect of gas puffing is not through a modification of power flow through the plasma boundary. A large scale instability associated with the density limit is ruled out as the cause of $\mathrm{H}$ $\mathrm{L}$ transition since the line average electron density in another $\mathrm{H}$-mode shot with a lower gas puffing rate exceeds that of the shot 62630. However as the following discussion shows, effects of a reduced particle confinement time at high densities may be significant.

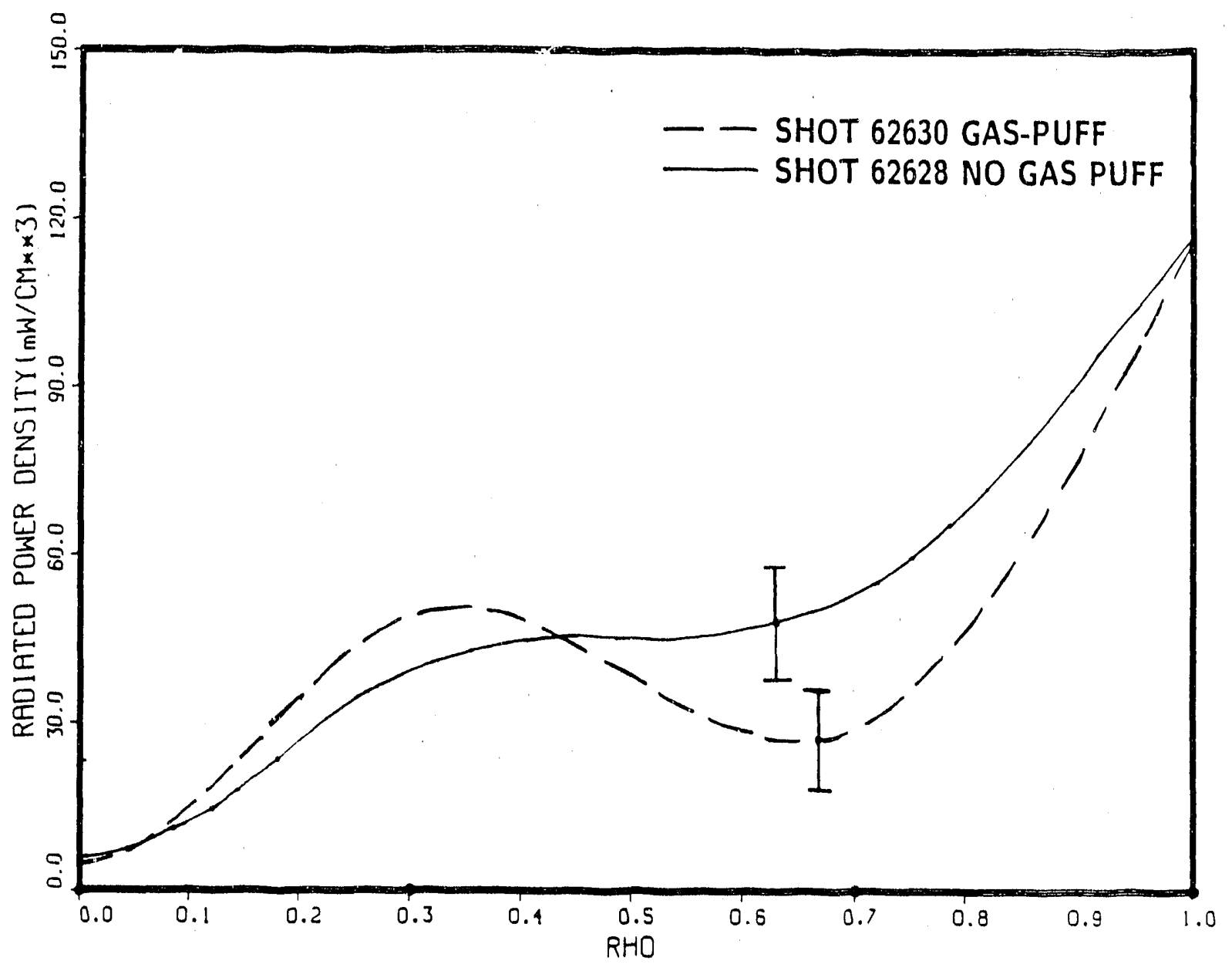

Fig. 8. Radiated power densities for shots 62630 (dashed) and 62628 (solid), obtained at $T \simeq 2.9$ s. The radiation profiles of the two shots are very similar just before the $\mathrm{H}$ - to L-mode transition of shot 62630 . 
In order to estimate the relative values of edge plasma collisionality for shots with and without gas puffing, we have compared the signals from the edge chords of a visible Bremsstrahlung array and a SXR diode array. The SXR signal is a sensitive function of the electron temperature and the visible Bremsstrahlung is a sensitive indicator of the electron density. From these diagnostic signals we have deuced that:

1. During gas puffing the edge collisionality (mainly due to a temperature decrease) gradually increases, without a corresponding decrease in confinement times, until the end of the shot or the occurrence of H-L transition.

2. The edge collisionality just before the H-L transition, of shot 62630 and other shots without gas puffing but with lower beam power which make an H-I transition, just before the H-L transition, are nearly identical.

3. The edge collisionality of shots that make an H-L transition are greater or equal to the lowest collisionality value reached in shots that remain in the $\mathrm{H}$-mode.

These results are consistent with the ASDEX results [5] that the edge collisionality is a key parameters for H-mode transition. However, in DIII-D, in contrast to ASDEX, in most of $\mathrm{H}$-mode plasmas the value of $\nu_{*}$, deduced from the measured values of $n_{\mathrm{e}}$ and $\mathrm{T}_{e}$ is greater than unity [3], therefor, $\nu_{*}$ is not the only controlling parameter determining the $\mathrm{H}-\mathrm{L}$ or $\mathrm{L}-\mathrm{H}$ transitions.

Angular momentum loss due to charge exchange of neutrals with the edge plasma ions and due to increased ion flux across the separatrix could be significant factors in the physics of the L-H transitions, and may explain the observed effects of neutrals on $\mathrm{H}$-mode confinement, as well as the a sharp reduction in the poloidal rotation speed during E.LMs observed in DIII-D. Recent spectroscopic observations in DIII-D [4] show a sudden jump in the poloidal rotation speed of the edge plasma, coinciding with the L-H transition. Recent theories $[6,7]$ show that a shear in the poloidal rotation velocity can suppress turbulent fluctuations, and result in an improved confinement. Shaing and Crume $[6,3 \mathrm{C}]$ have proposed a model of $\mathrm{L}-\mathrm{H}$ transition which is based on 
a bifurcation in the poloidal momentum balance equation. In this model, a torque due ion orbit losses within a poloidal gyroradius of the plasma boundary is balanced against the poloidal viscous drag. Thus it is plausible to expect that any mechanism such as charge exchange interaction that affects the edge momentum balance could also affect the $\mathrm{H}$-mode confinement. In the following we provide a rough estimate of the momentum source term due to charge exchange collisions in shot 62630 . Due to a lack of a complete data set from the same shot, we have inferred the plasma parameters from several similar shots. In the following, we adopt the notation of Ref. [30].

The momentum loss rate due to the charge exchange interactions is of the order of

$$
\dot{P}_{\mathrm{CE}} \approx N N_{0} v_{t} \sigma_{\mathrm{CE}}\left(v_{t}\right) M \mathrm{U}_{\mathrm{p}}
$$

where $N_{0}$ is the neutral density, $N$ is the ion density, $v_{t}$ is the ion thermal velocity, $U_{\mathrm{p}}$ is the poloidal rotation speed, and $\sigma_{\mathrm{CE}}\left(v_{t}\right)$ is the charge exchange cross section.

This momentum loss rate is significant when it is cornparable to the value of the dominant momentum sources. Using the momentum source term, due to pitch angle scattering of the trapped particles, as given in Ref. [30], we obtain an expression for the edge plasma neutral density above which charge exchange collisions are significant in the momentum balance equation.

$$
N_{0} \approx \frac{e \epsilon^{3 / 2}}{\mathrm{cM} \sigma_{\mathrm{CE}} R}\left(\frac{\Delta r}{v_{p}} \frac{B}{q}\right) \frac{\nu_{* i} G}{\left[\nu_{* i}+\left(\alpha U_{\mathrm{p}, \mathrm{m}}\right)^{4}\right]^{1 / 2}} \exp \left\{-\left[\left(\nu_{* i}+\alpha U_{\mathrm{p}, \mathrm{m}}\right)^{4}\right]^{1 / 2}\right\}
$$

where $\mathrm{U}_{\mathrm{p}, \mathrm{m}}=\mathrm{U}_{\mathrm{p}} B / v_{t} B_{\mathrm{p}}+\dot{\lambda}_{\mathrm{p} / 2}, \lambda_{\mathrm{p}}=-\rho_{\mathrm{p} i}\left(\frac{d P}{d r}\right) / \rho, \nu_{* i}=\nu R q / v_{t} \epsilon^{3 / 2}, q=\frac{\epsilon B}{B_{\mathrm{p}}}$, $\rho_{\mathrm{p} i}$ the ion poloidal gyroradius, and $\nu$ is the ion-ion collision frequency. 
For a typical $\mathrm{H}$-mode shot similar to shot 62630 , we obtain a neutral density of $N_{0} \approx 2 \times 10^{11} \mathrm{~cm}^{-3}$, where we have assumed $G=1, \alpha=0.7$, and $\Delta r=1 / 2 \rho_{\mathrm{pi}}$. This quantity should be compared with the edge neutral density just before the $\mathrm{H}-\mathrm{L}$ transition in shot 62630 , which is estimated to also be $\approx 10^{11} \mathrm{~cm}^{-3}$.

A possible momentum loss channel, indirectly attributable to the neutrals, is an enhancement in turbulent ion flux across the separatrix. During gas puffing in shot 62630 , the core neutral particle source increases to $\sim 350$ Torr $1 / \mathrm{s}$ without a significant change in the electron density. Therefore, to maintain particle balance, an equivalent number of ions and charge exchange neutrals must flow out across the separatrix. The mornentum loss due to the combined effect of ion transport and charge exchange contributions, $\dot{\mathrm{P}}_{\mathrm{T}}$, is

$$
\dot{\mathrm{P}}_{\mathrm{T}} \approx M \mathrm{U}_{\mathrm{P}} \nabla \cdot \Gamma \gtrsim \dot{P}_{\mathrm{CE}}
$$

since charge exchange losses account for a large fraction of the particle flux across the separatrix.

These rough estimates show that the effect of neutrals on edge momentum balance can be significant and need to be studied in more detail. 


\section{FUTURE PLANS}

DIII-D data $[3,4]$ and observations on several other devices [5] strongly suggest that $\mathrm{H}$-mode transition is controlled by processes within a few poloidal gyroradii of the plasma boundary. This region has considerable overlap with the radiative zone of the low- $Z$ impurities and the recycling neutral ionization profile, and therefore it is plausible that high fluxes of neutrals or low $Z$-impurities can have deleterious effects on $\mathrm{H}$-rnode confinement. The effect of neutrals and low- $Z$ impurities is but one of several conceivable ways that edge effects can influence the core plasma properties:

- Several investigators [31-34] have succeeded in affecting core plasma transport via limiter biasing or injection of electrons in the plasma boundary.

- Considering neoclassical ion transport near the separatrix, Hinton [35] has has correctly predicted the $\mathrm{H}$-mode power threshold dependence on the ion grad drift direction.

- Ono [36] and Jarbo [37], in separate experiments, have succeeded in driving a toroidal current, none inductively, through dc helicity injection at the separatrix.

- Stambaugh [38] has proposed divertor biasing as a means of access to the second region of ballooning stability and ELM control.

- Hinton and Stabler [39] have shown that, depending on the sign of the applied field, a poloidal clectric field, introduced through divertor biasing, can be used to enhance or reduce heat and particle fluxes across the separatrix.

Motivated by these considerations, we are in the processes of providing the means to test these and several other improvements on the simple open divertor, through the DIII-D advanced divertor program [40]. 
The implementation of the program is focused on the installation of a toroidally continuous electrode-baffle structure, as shown in Fig. 9 on the outboard lower divertor target area. The bias ring is electrically insulated from the vessel and the baffle plate. Either divertor bias or divertor baffle experiments can be made by adjusting the position of the separatrix with the DIII-D field shaping coils. The divertor ring is also an ideal site on which to mount alternate tile designs of either graphite or other materials. Since DIII-D can dynamically program the separatrix position during a discharge, a variety of experiments using selective exposure of materials to the divertor plasma is possible.

In the bias mode, [Fig. 9(a)], the outboard leg of the divertor rests on the divertor ring. An external power supply $(600 \mathrm{~V}, 20 \mathrm{kA})$ will drive a substantial current into the scrape-off layer. This current will flow along the field lines both poloidally and toroidally. This current and the associated poloidal electric field open a number of possibilities. Hinton and Staebler [39] have shown the resulting $\vec{E}_{p} \times \vec{B}_{T}$ radial drift can be as large as the normal outward particle flux from the plasma edge. Hence by choosing the sign of the bias, one can either add to the particle outflow to gain particle exhaust or subtract from (even reverse!) the particle outflow to improve particle (and possibly energy) confinement.

Calculations have shown that if the bias current diffuses slightly inward into the closed flux surfaces, then the resulting edge pedestal on the current density will open access to second stability at the edge, even in low $q$ plasmas.

The electrode configuration also injects dc helicity into the edge plasma. If this magnetic helicity diffuses inward, then direct non-inductive sustainment of the plasma current should result. The potential efficiency of helicity injection current drive is far greater than rf schemes and is an attractive option for tokamak reactors.

In the baffle mode [Fig. 9(b)], the outboard leg of the divertor will just miss the divertor ring. A substantial fraction of the recycled particles from the outer 

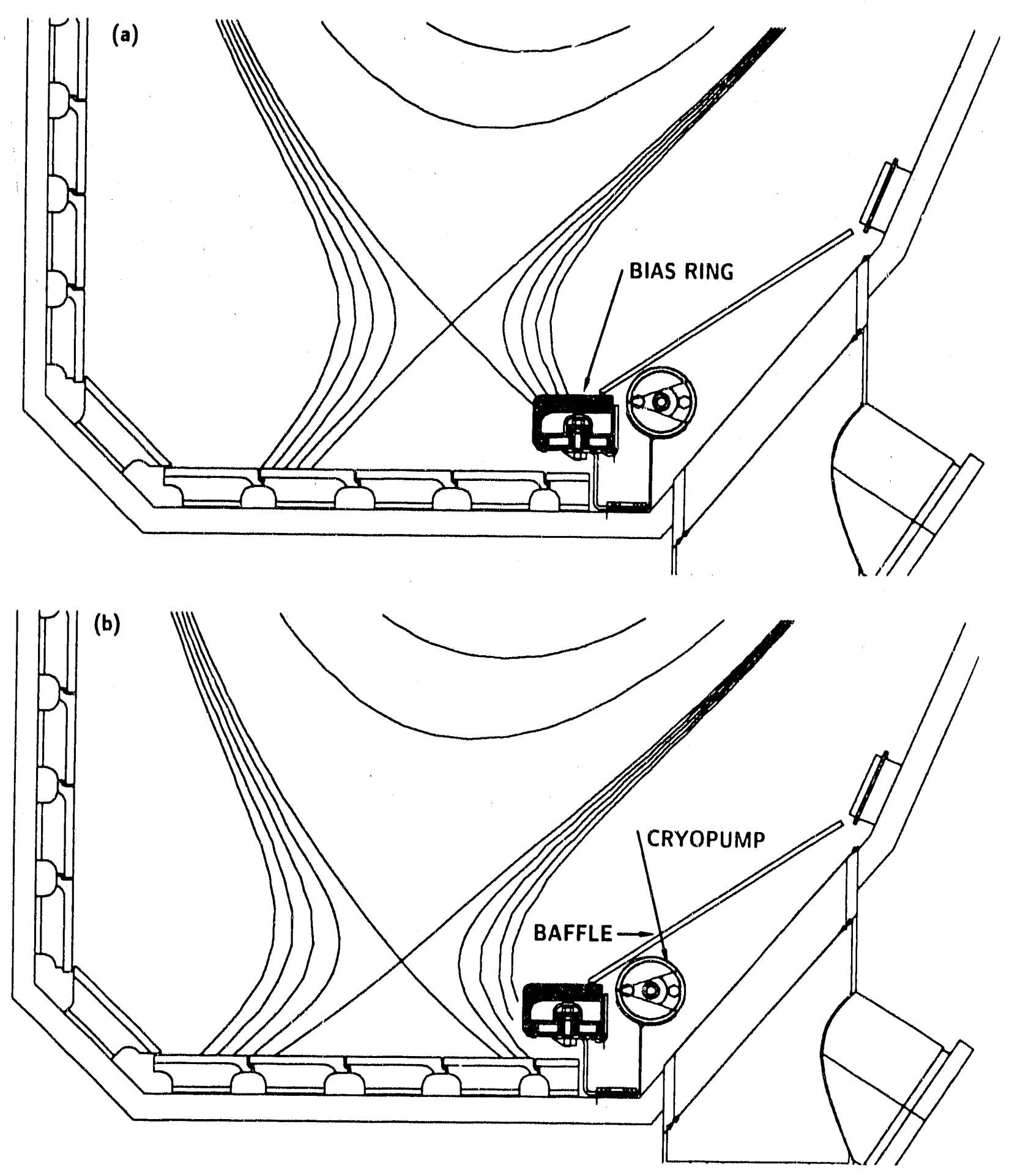

Fig. 9. Views of the ADP hardware. (a) In the biasing mode, the outboard leg of the divertor rides on a toroidal ring which is biased with respect to the vessel. In the baffle mode, the outboard leg of the divertor grazes the bias ring; a large fraction of the recycling neutrals are trapped under the baffle and are collected by the cryopump under the baffle. 
separatrix will be trapped under the divertor ring and associated baffle structure. DEGAS neutral code calculations show that, in absence of pumping, the neutral pressure under the baffle approaches $1 \mathrm{~m}$ Torr, however the neutral particle influx penetrating the core plasma decreases by a factor of 2 . A cryo pumping system, with a deuterium pumping speed of $50,000 \mathrm{l} / \mathrm{s}$, to be installed under the baffle, will provide a means of of active density control. Based on DEGAS calculations and analytical models, a particle removal rate of 20 Torr $1 / \mathrm{s}$, which is equal to the known external particle sources, should be attainable.

Erosion of the divertor target plates and the choice of the divertor material is a critical design issue for the next generation long pulse devices. The gravity of this problem is demonstrated by DIII-D observation that after less than 5 hours of plasma exposure, as much as $\sim 1 \mathrm{~mm}$ of graphite has eroded away from the corners of the graphite divertor tiles. Time integrated measurements of erosion and redeposition on the existing graphite divertor tiles in DIII-D, using mechanical profilometry, are already in progress [41]. A Divertor Materials Exposure System (DIMES) is under development. Our long term plans include development and installation of in situ erosion redeposition diagnostics, using thin film ellipsometry techniques, and testing of alternate divertor materials on the divertor bias ring. 


\section{SUMMARY}

We have shown that a combination of good vacuum practices, and helium glow and Taylor discharge cleaning can effectively eliminate all impurities except those due to sputtering of the wall materials. Carbonization was found effective in reducing the influx of metallic impurities.

Spreading the divertor heat load over a large surface area has allowed high power long pulse operation without any indication of carbon bloom. Large-amplitude variation on the heat flux to divertor tiles, and significant asymmetries of the divertor heat flux have been measured. It is verified that small misalignments and gaps between the tiles accounts for these variations. A combination of neoclassical drifts and classical geometrical factors qualitatively explains the observed asymmetries in the poloidal heat distribution.

A large neutral influx can adversely affect the $\mathrm{H}$-mode confinement. We have shown that angular momentum loss due to charge exchange losses or enhanced ion flux during high-flux gas puffing could be the cause of the confinement deterioration. 


\section{REFERENCES}

[1] G.L. Jackson, J. Nucl. Mater. 162-164, (1989).

[2] G.L. Jackson, et al., this conference.

[3] P. Gohil, M. Ali Mahdavi, L. Lao, et al., Phys. Rev. Lett. 61, 1603 (1988).

[4] R.J. Groebner, et al., in Proceedings of the Sixteenth European Conference on Controlled Fusion and Plasma Physics, Venice, Italy, (1989).

[5] F. Wagner, Phys. Rev. Lett. 53, 15 (1984).

[6] K.C. Shaing, Phys. of Fluids 31, (1989) 2249.

[7] H. Biglari, P. Diamond, Phys. of Fluids B2, (1990) 1.

[8] N.H. Brooks, and the DIII-D Group, J. Nucl. Mater. 145-147, (1987) 770.

[9] J. Winter, J. Nucl. Mater. 145-147, (1987).

[10] M.A. Mahdavi, C.J. Armentrout, F.P. Blau, G. Bramson, N.H. Brooks, et al., J. Nucl. Mater. 111-112, (1982).

[11] M. Ali Mahdavi, A. Kellman, P. Gohil, N. Brooks, et al., in Proceedings of the Sixteenth European Conference on Controlled Fusion and Plasma Physics, March 13-17, 1989, (EPS, Venice, Italy), Part I, p. 249.

[12] P. Gohil, General Atomics report GA-A20103, to be published.

[13] R.A. Hulse, Nucl. Technol. Fusion 3, (1983). 
[14] M.E. Perry, N. Brooks, D. Content, R. Hulse, et al., "Impurity Transport During DIII-D H-mode," General Atomics report GA-A19286, June 1989; submitted to Nucl. Fusion.

[15] D. Content, H.W. Moos, M.E. Perry, N. Brooks, et al., Nucl. Fusion 30, (1988) 701.

[16] D.N. Hill, R. Ellis, et al., Rev. Sci. Instru.

[17] G.H. Staebler, "Modell for Improved Divertor Confinement," General Atomics report GA-A19796 (Date?), submitted to Nucl. Fusion; N. Ueda, K. Itoh, S.I. Itoh, M. Tanaka, et al., J. Nucl. Mater. 162-164, (1989).

[18] B.J. Braams, "A Multi-Fluid Code for Simulation of the Edge Plasma in Tokamaks," NET Report NR.68 (1987).

[19] M.E. Rensink, et al., Bull. Am. Phys. Soc. 34, (1989).

[20] D. Hill, Bull. Am. Phys. Soc.33, (1988).

[21] D.N. Hill, Proceedings of this conference.

[22] G.H. Staebler, F.L. Hinton, Nucl. Fusion 29, (1989).

[23] P.J. Harbour, D.D.R. Summers, et al., J. Nucl. Mater. 162-164, (1989).

[24] P.C. Stangeby, "Currents in the Scrape Off Layer of Diverted Tokamaks and Power to the Divertor Plates," submitted to Nucl. Fusion.

[25] M.J. Schaffer, B.J. Leikind, "Observation of Circulating Currents in Tokamak Scrape-Off Layer," General Atomics report GA-A20128.

[26] T.T.C. Jones, J.W. Cuthbertson, J. Ehrenberg, et al., J. Nucl. Mater. 163-165 (1988).

[27] J. Ehrenberg, et al., J. Nucl. Mater. 163-165 (1988).

[28] S.M. Kay, M.G. Bell, K. Bol, et al., J. Nucl. Mater. 121 (1984). 
[29] ASDEX 'T̃am, Nucl Fusion 29, (1989).

[30] K.C. Shaing and E.C. Crume, Jr., Phys. Rev. Lett. 21, (1989), 63.

[31] R. Taylor, etal. IAEA, 1982.

[32] M. Shimada, etal. APS, 1985.

[33] T.S. Taylor, et al. Phys. Rev. Lett., (1989).

[34] R. Conn, etal. in Proceedings of IEA, Kyoto, 1986.

[35] F.L. Hinton, Nucl. Fusion 25, (1985) 1457.

[36] M. Ono, G.S. Greene, D. Darrow, C. Forest, H. Park, T.H. Stix, Phys. Rev. Lett. 59, (1987) 2165.

[37] T.R. Jarboe, I. Hening, A.R. Sherwood, C.W. Barnes, H.W. Heida, Phys. Rev. Lett. 51, (1983) 39.

[38] R. Stambaugh, Private communications.

[39] F.L. Hinton and G.M. Staebler, General Atomics Report GA-A19356, March 1989.

[40] M.A. Mahdavi, M. Schaffer, P. Mioduszewski, et al., "The DIII-D Collaborative Advanced Divertor Program," General Atomics report GA-A19547, February 1989.

[41] D. Buchenauer, this conference. 


\section{ACKNOWLEDGMENT}

The authors wish to thank Drs. F. Hinton and R. Miller for useful discussions. This work was supported by the U.S. Department of Energy under Contract Nos. DEAC03-89ER51114, DE-FG03-89-ER51121, W-7405-ENG-48, DE-AC03-84OR21400, and DE-AC03-76DP00789. 

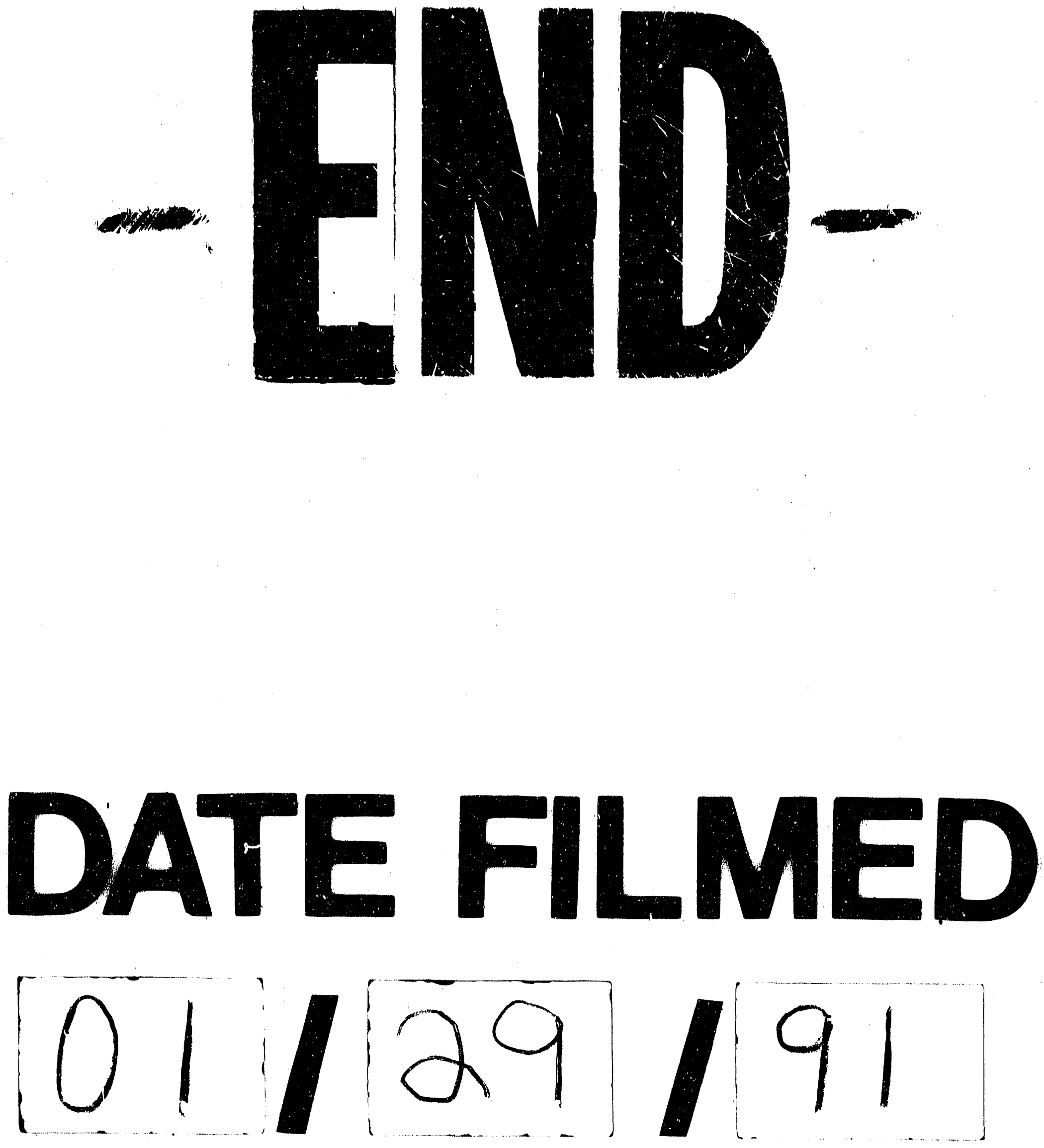

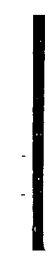


